\title{
Functional genomic studies on an immune- and antiviral-related gene of MyD88 in orange-spotted grouper, Epinephelus coioides
}

\author{
YAN Yang $^{1 \dagger}$, CUI HuaChun ${ }^{2 \dagger}$, WEI JingGuang ${ }^{1}$, HUANG YouHua ${ }^{1}$, HUANG XiaoHong ${ }^{1} \&$ \\ QIN QiWei ${ }^{1 *}$
}

\author{
${ }^{1}$ Key Laboratory of Marine Bio-resources Sustainable Utilization, South China Sea Institute of Oceanology, Chinese Academy of Sciences, \\ Guangzhou 510301, China; \\ ${ }^{2}$ State Key Laboratory of Biocontrol, School of Life Sciences, Sun Yat-sen University, Guangzhou 510275, China
}

Received November 3, 2011; accepted March 8, 2012; published online July 12, 2012

\begin{abstract}
Myeloid differentiation factor 88 (MyD88) is a universal adaptor protein involved in Toll-like receptors and in interleukin-1 receptor-induced nuclear factor-kappaB (NF- $\mathrm{KB}$ ) activation. In this study, a new MyD88 gene (designated as $O g-M y D 88$ ) was cloned from orange-spotted grouper, Epinephelus coioides, based on the expressed sequence tag (EST) obtained following Roche 454 GS-FLX ${ }^{\mathrm{TM}}$ sequencing. The full-length Og-MyD88 cDNA is composed of $1682 \mathrm{bp}$ and encodes a deduced polypeptide of 289 amino acids with $86 \%$ homology to MyD88 of Siniperca chuatsi. The deduced amino acid sequence of Og-MyD88 contains a typical death domain at the amino terminus and a conserved Toll/IL-1R (TIR) domain at the carboxyl terminus, as well as three highly conserved motifs (Box1, Box2 and Box3) within the C-terminal TIR domain. In healthy fish, Og-MyD88 was found to be strongly expressed in immune-related tissues, including the spleen, head kidney, kidney, liver, skin and intestine, with lower expression in heart, stomach, brain and muscle. Transcripts of Og-MyD88 were found to be markedly up-regulated in fish spleen after challenge with Singapore grouper iridovirus (SGIV), a highly lethal viral pathogen to grouper fish. Furthermore, the full length Og-MyD88 and its N-terminal death domain were capable of inducing NF- $\mathrm{BB}$ activity in HEK-293 cells. Overexpressed Og-MyD88 showed the ability to inhibit replication of SGIV in grouper spleen (GS) cells. These results suggest that Og-MyD88 is involved in the grouper immune response to invasion of viral pathogens and may share similar functions to those observed in higher vertebrates.
\end{abstract}

myeloid differentiation factor 88 (MyD88), Epinephelus coioides, expression analysis, NF- $\mathrm{kB}$ activation, immune response, SGIV

Citation: Yan Y, Cui H C, Wei J G, et al. Functional genomic studies on an immune- and antiviral-related gene of MyD88 in orange-spotted grouper, Epinephelus coioides. Chin Sci Bull, 2012, 57: 3277-3287, doi: 10.1007/s11434-012-5126-y

The immune system in teleost fish consists of innate and adaptive functions, which represent the host defense lines against infective bacterial and viral agents. As in other vertebrates, the innate immunity of fish provides immediate defense in host protection against invading microbial pathogens [1-5]. Early detection of invading microorganisms, such as viruses and infectious bacteria, depends on host pattern recognition receptors (PRRs), which exist either at the cell surface or in the cytoplasm and include transmembrane toll-like receptors (TLRs) and cytosolic PRRs (for example RIG-I, MDA5 and PKR) [6,7]. In mammals, TLR

\footnotetext{
$\dagger$ These authors contributed equally to this work.

*Corresponding author (email: qinqw@ scsio.ac.cn)
}

family members act as primary sensors that recognize a wide variety of highly structurally conserved pathogen-associated molecular patterns (PAMPs), derived from bacteria, viruses, fungi and protozoa. TLRs then elicit innate immune responses, including universal activation of the transcription factor nuclear factor-kappaB $(\mathrm{NF}-\kappa \mathrm{B})$ and interferon (IFN) signaling in immune cells $[5,8]$.

To date, more than 13 TLR members have been identified, and demonstrated to detect distinct PAMPs within various microorganisms [5,9]. All reported mammalian TLRs are single-pass transmembrane proteins composed of $\mathrm{N}$-terminal extracellular leucine-rich repeats (LRRs). They are responsible for the recognition of specific PAMPs, a 
membrane-spanning domain and a conserved C-terminal cytosolic Toll/interleukin-1 receptor (TIR) domain. The TIR region of TLRs is required for initiating downstream signaling via association with intracellular TIR-domaincontaining adaptors [10], including Myeloid differentiation factor 88 (MyD88), TIR-domain-containing adaptor protein (TIRAP or Mal) [11], TIR-domain-containing adaptor-inducing IFN (TRIF or TICAM-1) [12,13], TRIF-related adaptor molecule (TRAM or TICAM-2) and Sterile-alpha and Armadillo-motif-containing protein (SARM) [14,15]. Generally, signaling pathways through TLRs can be broadly categorized into two classes: MyD88-dependent signaling and MyD88-independent/TRIF-dependent signaling [10]. Among the five TLR intracellular adaptors, MyD88 is reported to be recruited by most TLRs, except TLR3, which recruits TRIF as its adaptor protein and leads to activation of interferon regulatory factors (IRFs) and production of type-I IFNs, which mediate the cellular antiviral responses $[12,13,16]$.

MyD88 was originally characterized as a myeloid differentiation primary response protein, activated during terminal differentiation of murine M1D+ myeloid precursor cells, following induction by IL-6 treatment [17]. Subsequently, a variety of MyD88 genes have been extensively studied in other species, including human [18], mouse [19], chicken [20], frog [21], scallop [22] and fruit fly [23]. All reported MyD88 genes consist of two conserved domains comprising an amino terminal death domain and a typical TIR domain at the carboxyl terminal region. In mammals, after recognition of PAMPs by cellular TLRs, the C-terminal TIR domain of MyD88 interacts directly with the TIR domains of certain TLRs, interleukin-1 receptor (IL-1R) or other adaptors (TRAM or TIRAP). Following this, the death domain of MyD88 mediates the interaction with the corresponding domain in IL-1R-associated kinases (IRAKs), leading to recruitment of downstream immune molecules and resulting in activation of NF- $\kappa \mathrm{B}$, IRFs and induction of proinflammatory cytokines or antiviral genes $[10,24,25]$. Until now, MyD88 orthologs have been identified in several fish species, including zebrafish [26], rainbow trout [27], Japanese flounder [28], Atlantic salmon [29], large yellow croaker and rock bream [30,31]. However, the roles of MyD88 in fish innate immune responses, especially in combating virus infection, have not been fully elucidated.

Orange-spotted grouper, Epinephelus coioides, one of the major maricultured species in China and Southeast Asian countries, are an expensive and popular seafood fish. In recent years, with the rapid development of intensive marine fish farming, viral pathogens, particularly iridoviruses like Singapore grouper iridovirus (SGIV), have affected the grouper aquaculture industry causing heavy economic losses $[32,33]$. In comparison with other commercially important fish, information on viral immunological mechanisms in grouper is scarce. A better understanding of viral PAMPs-related TLR signaling in grouper will be helpful in controlling viral disease.

To find immune-relevant factors responsible for virus resistance or infection, 454-pyrosequencing methodology was employed for large-scale characterization of expressed genes in SGIV-infected grouper spleen, using the Roche 454 GS-FLX ${ }^{\mathrm{TM}}$ Titanium System. From the grouper cDNA sequence database, an expressed sequence tag (EST) of the MyD88 gene was identified using the Basic Local Alignment Search Tool (BLAST) within the National Center for Biotechnology Information (NCBI) website (http://www. ncbi.nlm.nih.gov/BLAST). In the present study, the full length cDNA of MyD88 was cloned from E. coioides. The sequence characteristics and the temporal expression profiles of Og-MyD88 were investigated. In particular, NF- $\mathrm{BB}$ activity induced by different functional domains of Og-MyD88 was studied using the luciferase reporter assay in HEK293 cells and the anti-viral effect of Og-MyD88 against SGIV infection was analyzed in grouper spleen (GS) cells.

\section{Materials and methods}

\subsection{Fish and cell lines}

Juvenile orange-spotted grouper, E. coioides, approximately $50 \mathrm{~g}$ in body weight and 6 months old, were purchased from a fish farm in Zhanjiang, Guangdong Province, China. Fish were maintained in a laboratory recirculating seawater system at $25-30^{\circ} \mathrm{C}$ for two weeks. The fish were anesthetized with tricaine methanesulfonate (MS222, $100 \mathrm{mg} \mathrm{L}^{-1}$, Sigma, USA) before euthanasia. A series of tissue samples, including heart, liver, spleen, intestine, brain, skin, muscle and stomach, were dissected from the euthanized fish and immediately frozen by liquid nitrogen, followed by storage at $-80^{\circ} \mathrm{C}$ until required.

GS cells, derived from the spleen of $E$. coioides, were grown in Leibovitz's L-15 medium containing $10 \%$ fetal bovine serum (FBS, Gibco, USA) at $27^{\circ} \mathrm{C}$ [34]. HEK-293 cells were maintained in Eagle's minimum essential medium (EMEM) supplemented with 10\% FBS, antibiotics (60 $\mathrm{U} \mathrm{L}^{-1}$ penicillin, $100 \mu \mathrm{g} \mathrm{L}^{-1}$ streptomycin) and $4 \mathrm{mmol} \mathrm{L}^{-1}$ $L$-glutamine in a humidified atmosphere containing $5 \% \mathrm{CO}_{2}$ at $37^{\circ} \mathrm{C}$.

\subsection{SGIV challenge in fish}

SGIV was first isolated from the brown-spotted grouper, $E$. tauvina, and the propagation of SGIV was performed as described previously [33]. Briefly, GP cells derived from the brown-spotted grouper, E. tauvina, were cultured in EMEM containing $10 \% \mathrm{FBS}$ at $25^{\circ} \mathrm{C}$. Virus was inoculated onto confluent monolayers of the GP cell cultures at a multiplicity of infection (MOI) of approximately 0.1 . When the cytopathogenic effect (CPE) was sufficient, the medium containing SGIV was harvested and centrifuged at $3000 \times g$ for $10 \mathrm{~min}$ at $4^{\circ} \mathrm{C}$ and the SGIV-containing supernatant was 
collected and stored at $-80^{\circ} \mathrm{C}$ until required.

The in vivo pathogenicity experiment was performed by intraperitoneal injection (i.p.). Before injection, fish were anesthetized with MS222. Each control and challenged sample was injected with $50 \mu \mathrm{L}$ PBS and SGIV at a concentration of $1 \times 10^{5} \mathrm{TCID}_{50} \mathrm{~mL}^{-1}$. The infectious dose of SGIV for in vivo challenge was optimized by our previous studies and was less than the lethal dose. Grouper spleens (5 fish per group) were collected at different time points post-injection and immediately snap-frozen in liquid nitrogen, followed by storage at $-80^{\circ} \mathrm{C}$ until required for RNA extraction.

\subsection{RNA extraction and cDNA synthesis}

Total RNA was extracted using TRIzol Reagent (Invitrogen, USA) according to the manufacturer's protocol. The quality of the RNA was assessed by electrophoresis on $1.0 \%$ agarose gel. RNA samples were treated with DNase I to remove contaminated genomic DNA using the Turbo DNA-free kit (Ambion, USA). Total RNA was reverse transcribed to synthesize the first-strand cDNA using the ReverTra Ace kit (Toyobo, Japan) according to the manufacturer's instructions.

\subsection{Full-length cDNA cloning of orange-spotted grouper MyD88}

We established a grouper spleen cDNA sequence database using the Roche 454 Genome Sequencer FLX System (GS-FLX ${ }^{\mathrm{TM}}$, Roche 454 Life Sciences, USA) [35]. Briefly, messenger RNA was isolated from total spleen RNA using the kit reagents of the FastTrack ${ }^{\circledR} 2.0$ mRNA isolation kit (Invitrogen). First strand cDNA synthesis and normalization were carried out with the Creator ${ }^{\mathrm{TM}}$ SMARTTM CDNA library construction kit (Clontech, USA) and Trimmer cDNA normalization kit (Evrogen, Russia) respectively. Sequencing was then performed using a Roche GS FLX Titanium instrument. After blasting the raw sequences against the NCBI database, a 596-bp EST of the MyD88 gene was identified.
Based on the identified EST sequence of MyD88 from the grouper cDNA sequence database, the 5' and 3' ends of Og-MyD88 cDNA were obtained using the Rapid Amplification of cDNA Ends (RACE) approach. Briefly, three specific primers, 5'Og-MyD88-R1, 5'Og-MyD88-R2 and 3'OgMyD88-F1, were designed based on the initial identified EST sequence of MyD88 (Table 1). The first-strand cDNA templates for 5' RACE and 3' RACE were synthesized from spleen total RNA with the SMART TM RACE cDNA amplification kit (Clontech) according to the manufacturer's protocol. For 5' RACE, the gene specific primer 5'OgMyD88-R1 and universal primer mix (UPM, supplied in the kit), were used for first round PCR, and primer 5'Og-MyD88-R2 and nested universal primer (NUP, supplied in the kit) were used in the nested PCR. For 3' RACE, the amplification was carried out with the primer 3'Og-MyD88-F1 and NUP. The PCR reactions were conducted in a Bio-Rad Thermocycler (Bio-Rad, USA) at $94^{\circ} \mathrm{C}$ for $3 \mathrm{~min}$, followed by 5 cycles of $94^{\circ} \mathrm{C}$ for $30 \mathrm{~s}$ and $72^{\circ} \mathrm{C}$ for $2 \mathrm{~min}, 5$ cycles of $94^{\circ} \mathrm{C}$ for $30 \mathrm{~s}, 70^{\circ} \mathrm{C}$ for $30 \mathrm{~s}$ and $72^{\circ} \mathrm{C}$ for $2 \mathrm{~min}, 25$ cycles of $94^{\circ} \mathrm{C}$ for $30 \mathrm{~s}, 68^{\circ} \mathrm{C}$ for $30 \mathrm{~s}$ and $72^{\circ} \mathrm{C}$ for $2 \mathrm{~min}$.

The resulting fragments of $5^{\prime}$ and $3^{\prime}$ RACE were separated on $1.0 \%$ agarose gel and purified using the AxyPrep ${ }^{\mathrm{TM}}$ DNA gel extraction kit (Axygen, USA). The purified fragments were then cloned into the pMD-18T vector (TaKaRa, Japan) using the TA cloning strategy and sequenced using the ABI 3730 sequencer system (Applied Biosystems, USA).

\subsection{Analysis of nucleotide and amino acid sequences}

The nucleotide and predicted amino acid sequences of Og-MyD88 were analyzed using BioEdit and Expasy search programs (http://au.exasy.org/tools/). The similarity of Og-MyD88 with other MyD88 variants was analyzed using the NCBI BLASTP search program (http://www.ncbi.nlm. nih.gov/blast). The domain structures were predicted using the SMART program (http://smart.embl-heidelberg.de/). Multiple amino acid sequence alignments of the reported MyD88 variants was obtained using ClustalX 1.83(http:// www.ebi.ac.uk/clustalW/) and GeneDoc software. The

Table 1 Sequence of primers used in this study

\begin{tabular}{ll}
\hline \multicolumn{1}{c}{ Primer } & Sequence $\left(5^{\prime} \rightarrow 3^{\prime}\right)$ \\
\hline 5'Og-MyD88-R1 & GTG ATA CCG AAC CTC TCT GGG GTG CGA \\
5'Og-MyD88-R2 & CGA GCC CCC ACT TCA GGT CCC AGA G \\
3'Og-MyD88-F1 & CAG TGA AGT ACA AGC CAA TGA CAA AGC C \\
pcDNA-MyD88-F & GCG GAT CCA TGG CGT GTA AGG ACC CAG AAG T \\
pcDNA-MyD88-M2F & GCG GAT CCA TGG CCC CTG AGC TGT TTG ATG CCT \\
pcDNA-MyD88-M1R & GCG AAT TCT TAA CCC TCG GGG TCG TCC TCC AGG \\
pcDNA-MyD88-R & GCG AAT TCT TAC GGC AGC GAG AGC GCC T \\
RT-MyD88-F & TGC CTT CAT CTG CTA CTG CC \\
RT-MyD88-R & CCA CCA TCC GCT TAC ACC T \\
RT-Actin-F & TAC GAG CTG CCT GAC GGA CA \\
RT-Actin-R & GGC TGT GAT CTC CTT CTG CA
\end{tabular}


phylogenetic tree was constructed using MEGA 3.1 software (http://megasoftware.net).

\subsection{RT-qPCR analysis of Og-MyD88 mRNA expression profiles}

Total RNA was extracted from healthy grouper tissues, including liver, spleen, head kidney, kidney, brain, intestine, heart, skin, muscle and stomach, using TRIzol Reagent (Invitrogen) for Og-MyD88 tissue distribution analysis. Total RNA was also extracted from fish spleens at different time points after challenging with SGIV. Each sample contained 5 independent individuals to eliminate interspecies variation. First-strand cDNA was synthesized with ReverTra Ace $^{\circledR}$ qPCR RT Kit (Toyobo) and RT-qPCR was employed to detect the Og-MyD88 expression profile, using $\beta$-actin as a reference gene.

The RT-qPCR primers, RT-MyD88-F/RT-MyD88-R and RT-Actin-F/RT-Actin-R (Table 1), shared similar Tm values and were designed to amplify $\sim 250$ bp length fragments. RT-qPCR was performed on a Roche LightCycler $^{\circledR} 480$ Real-Time PCR system (Roche, Switzerland) using $2 \times$ SYBR Green Real-time PCR Mix (Toyobo). PCR amplification was performed in triplicate wells, using the cycling parameters: $94^{\circ} \mathrm{C}$ for $5 \mathrm{~min}$, followed by 40 cycles of $5 \mathrm{~s}$ at $94^{\circ} \mathrm{C}, 10 \mathrm{~s}$ at $60^{\circ} \mathrm{C}$ and $15 \mathrm{~s}$ at $72^{\circ} \mathrm{C}$.

All data are presented in terms of relative mRNA expression as mean $\pm \mathrm{SD}$, and were subjected to a Student's $t$-test. Differences were considered statistically significant at $P<0.05$.

\subsection{Luciferase reporter assay}

Og-MyD88 expression vector, pcDNA-MyD88, was constructed based on the vector pcDNA3.1 (+) (Invitrogen). Primers pcDNA-MyD88-F and pcDNA-MyD88-R (Table 1) were used to amplify the ORF sequence of Og-MyD88 from grouper spleen cDNA and the target PCR product was digested and subcloned into the BamH I and Xho I sites of the pcDNA3.1 (+) vector. In addition, two recombinant plasmids expressing mutant versions of Og-MyD88 (termed M1 and M2) were constructed using primer pairs pcDNAMyD88-F/pcDNA-MyD88-M1R and pcDNA-MyD88M2F/pcDNA-MyD88-R respectively (Table 1). In detail, pcDNA-MyD88-M1 encodes a polypeptide within the $\mathrm{N}$-terminal 150 amino acids containing the predicted death domain and pcDNA-MyD88-M2 encodes the C-terminal TIR domain of Og-MyD88. The recombinant plasmids were transformed into $E$. coli $\mathrm{DH} 5 \alpha$ and subjected to nucleotide sequencing.

HEK-293 cells, cultured in 24-well plates for approximately $18 \mathrm{~h}$, were transiently transfected with $200 \mathrm{ng}$ pNF-кB-Luc (Clontech), $50 \mathrm{ng}$ pRL-TK vector (Promega), together with $400 \mathrm{ng}$ indicated Og- MyD88 expression vector or pcDNA3.1 empty vector, using Lipofectamine ${ }^{\mathrm{TM}}$
2000 Reagent (Invitrogen). Cells were harvested $24 \mathrm{~h}$ after transfection and the Firefly and Renilla luciferase activities of total cell lysates were measured consecutively with a Dual-Luciferase $^{\circledR}$ assay system (Promega) on a PerkinElmer VICTOR $^{\text {TM }}$ X5 instrument (PerkinElmer, USA). Firefly luciferase activity was normalized to the constitutively expressed Renilla luciferase activity and expressed as the fold stimulation relative to the pcDNA3.1 transfected control cells.

All data are represented as mean relative stimulation \pm $\mathrm{SD}$ and were subjected to Student's $t$-test. Differences were considered statistically significant at $P<0.05$.

\subsection{SGIV replication kinetics assay}

(i) Selection of GS cells stably expressing Og-MyD88. To obtain cells that stably expressed Og-MyD88, GS cells were transiently transfected with pcDNA-MyD88 or empty vector and then selected with $800 \mu \mathrm{g} \mathrm{mL}^{-1} \mathrm{G} 418$ (Gibco, USA). In detail, GS cells cultured in 24-well plates for $18 \mathrm{~h}$ were transiently transfected, either with $600 \mathrm{ng}$ pcDNA3.1 (+) empty vector or $600 \mathrm{ng}$ pcDNA-MyD88, using Lipofectamine 2000 Reagent (Invitrogen) according to the manufacturer's instructions. Following transfection for $48 \mathrm{~h}$, G418 (Gibco) was added to the medium at a final concentration of $800 \mu \mathrm{g} \mathrm{mL}^{-1}$. After 6 weeks of selective culturing, the transfected cells were confirmed, using RT-qPCR, to detect the transcripts of Og-MyD88. The stably pcDNA3.1 transfected and pcDNA-MyD88 transfected GS cells were termed as GS/pcDNA and GS/pcDNA- MyD88 cells respectively. The stably transfected cells were maintained in Leibovitz's L-15 medium supplemented with 10\% FBS and $800 \mu \mathrm{g} \mathrm{mL} \mathrm{L}^{-1} \mathrm{G} 418$ (Gibco) at $25^{\circ} \mathrm{C}$.

(ii) Viral replication kinetics assay. To investigate the impact of Og-MyD88 on SGIV infection in vitro, viral replication kinetics were evaluated based on SGIV propagation in GS/pcDNA-MyD88 and GS/pcDNA cells. In detail, the cell lines of GS/pcDNA-MyD88 and GS/pcDNA $\left(1 \times 10^{5}\right.$ per well) were separately seeded in 24-well plates, grown for $24 \mathrm{~h}$ and infected with SGIV at an MOI of 0.5. The virus-infected cell lysates were collected at the indicated time points $(0,6,12,18,24,36,48$ and $72 \mathrm{~h}$ post-infection, hpi) and were used to infect GS cells cultured in 96-well plates after serial dilution. The virus titers of the collected lysates were determined using a 50\% tissue culture infectious dose $\left(\mathrm{TCID}_{50}\right)$ assay after $72 \mathrm{~h}$ of incubation [36]. Each sample was measured in triplicate. Morphological changes were observed daily using light microscopy (Leica, Germany).

\section{Results}

\subsection{Cloning and sequence characterization of Og-MyD88 gene}

Based on the identified EST sequence of Og-MyD88 in the 
grouper cDNA sequence database, three gene-specific primers were designed for the rapid amplification of the $5^{\prime}$ and $3^{\prime}$ cDNA ends (Table 1). The full-length cDNA of OgMyD88 was amplified using the SMART RACE cDNA amplification kit (Clontech). The cDNA sequence of Og-MyD88 was deposited in GenBank under accession number HM590879. Og-MyD88 cDNA is composed of $1682 \mathrm{bp}$, containing a $120 \mathrm{bp} 5^{\prime}$-terminal untranslated region (UTR), 692 bp 3'-UTR and an open reading frame (ORF) of $870 \mathrm{bp}$, which encodes a putative protein of 289 amino acids with a predicted molecular mass of $33.2 \mathrm{kD}$ (Figure 1). The start (ATG) and stop (TAA) codons were found at nucleotide positions 121-123 and 988-990 from the 5 ' end of the cDNA respectively. Two mRNA instability motifs $\left({ }^{1303}\right.$ ATTTA $^{1307},{ }^{1353}$ ATTTA $\left.^{1357}\right)$ and a consensus polyadenylation signal sequence $\left({ }^{1637}\right.$ AATAAA $\left.^{1642}\right), 13$ bp upstream of the poly-A tail, were found in the 3'-UTR of Og-MyD88 cDNA.

Computer-assisted analysis showed that, like other re- ported MyD88 sequences, the putative Og-MyD88 protein possesses two conserved domains: a death domain at positions 12-104 of the amino terminus and a C-terminal TIR domain at positions 153-289. Sequence analysis of Og-MyD88 revealed the presence of three highly conserved motifs (Box1: FDAFICYCQ; Box2: LCVFDRDVLPGSC; Box3: FWVRL) within the TIR domain that corresponded to those found in other fish species, chicken, frog and mammals (Figure 1).

\subsection{Sequence comparison and homology analysis of Og-MyD88}

To determine the evolutionary relationship of Og-MyD88 with other MyD88 variants, the deduced amino acid sequence of Og-MyD88 was blasted against the NCBI data base. Og-MyD88 showed highest amino acid homology to the MyD88 of mandarin fish $(86 \%)$ and shared more than $70 \%$ homology to the MyD88 variants reported in other fish

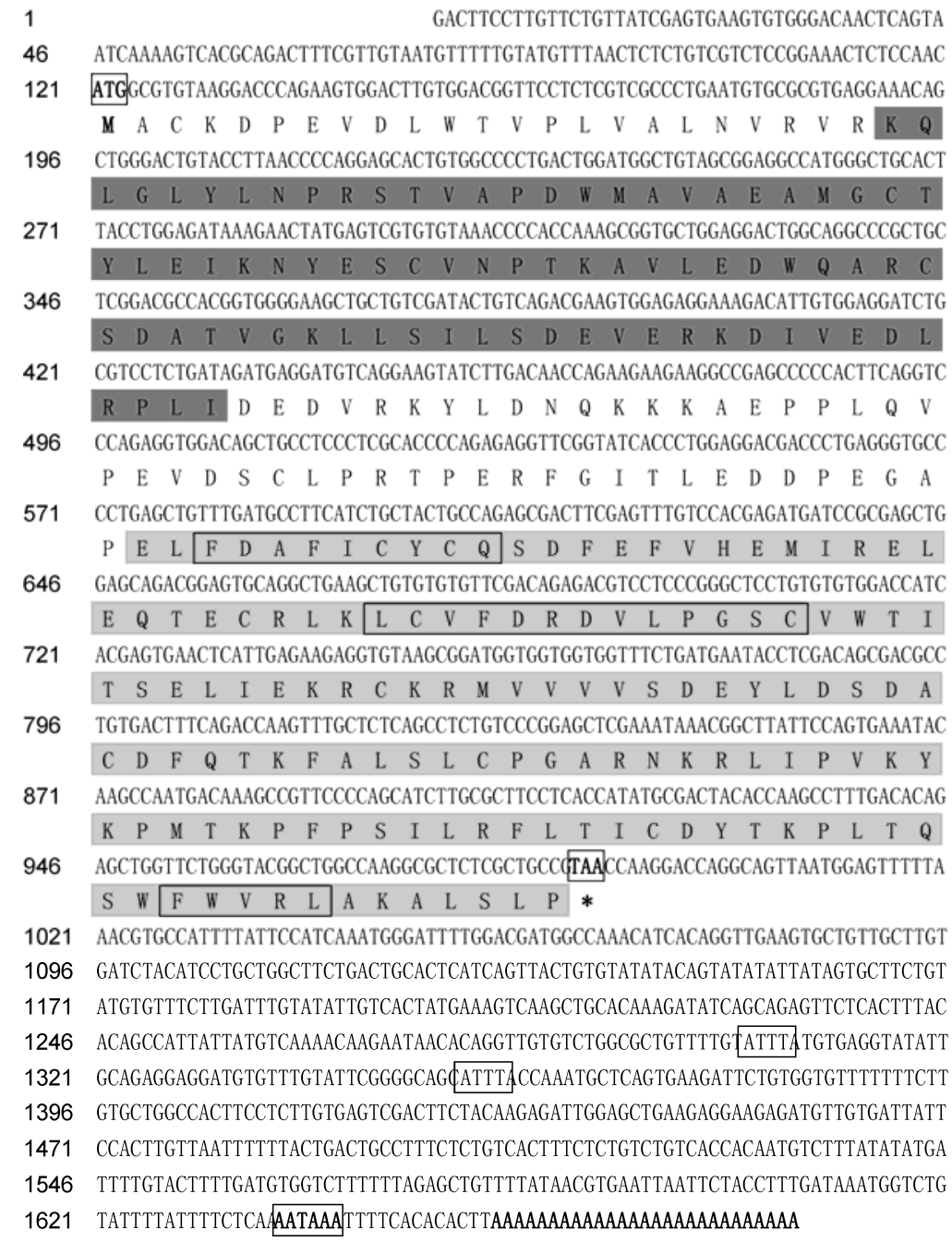

Figure 1 Nucleotide and deduced amino acid sequences of Og-MyD88. The predicted death domain (amino acids 12-104) and the TIR domain (amino acids 153-289) are shaded in dark and light gray respectively. The start codon (ATG), stop codon (TAA), poly (A) signal sequence (AATAAA), mRNA instability motifs (ATTTA) and three highly conserved boxes within the TIR domain are boxed. 
species, including Larimichthys crocea, Paralichthys olivaceus, Takifugu rubripes, Salmo salar, Oncorhynchus mykiss, Ictalurus punctatus and Danio rerio to name a few.

Multiple-sequence alignment of reported MyD88 variants were performed and a MyD88 phylogenetic tree was constructed by ClustalX 1.83 and MEGA 3.1 using the neighbor-joining method. All selected MyD88 sequences share high conservation at the death domain, TIR domain and three box regions (Figure 2). The phylogenetic tree consists of two major branches: invertebrate MyD88 and vertebrate MyD88. Og-MyD88 was clustered into a second subgroup termed fish MyD88 variants, which belong to the MyD88 vertebrate subgroup, together with MyD88 in Xenopus tropicalis, Gallus gallus and mammals. Within the tree, Og-MyD88 was phylogenetically closer to MyD88s of L. crocea, S. salar and O. mykiss (Figure 3).

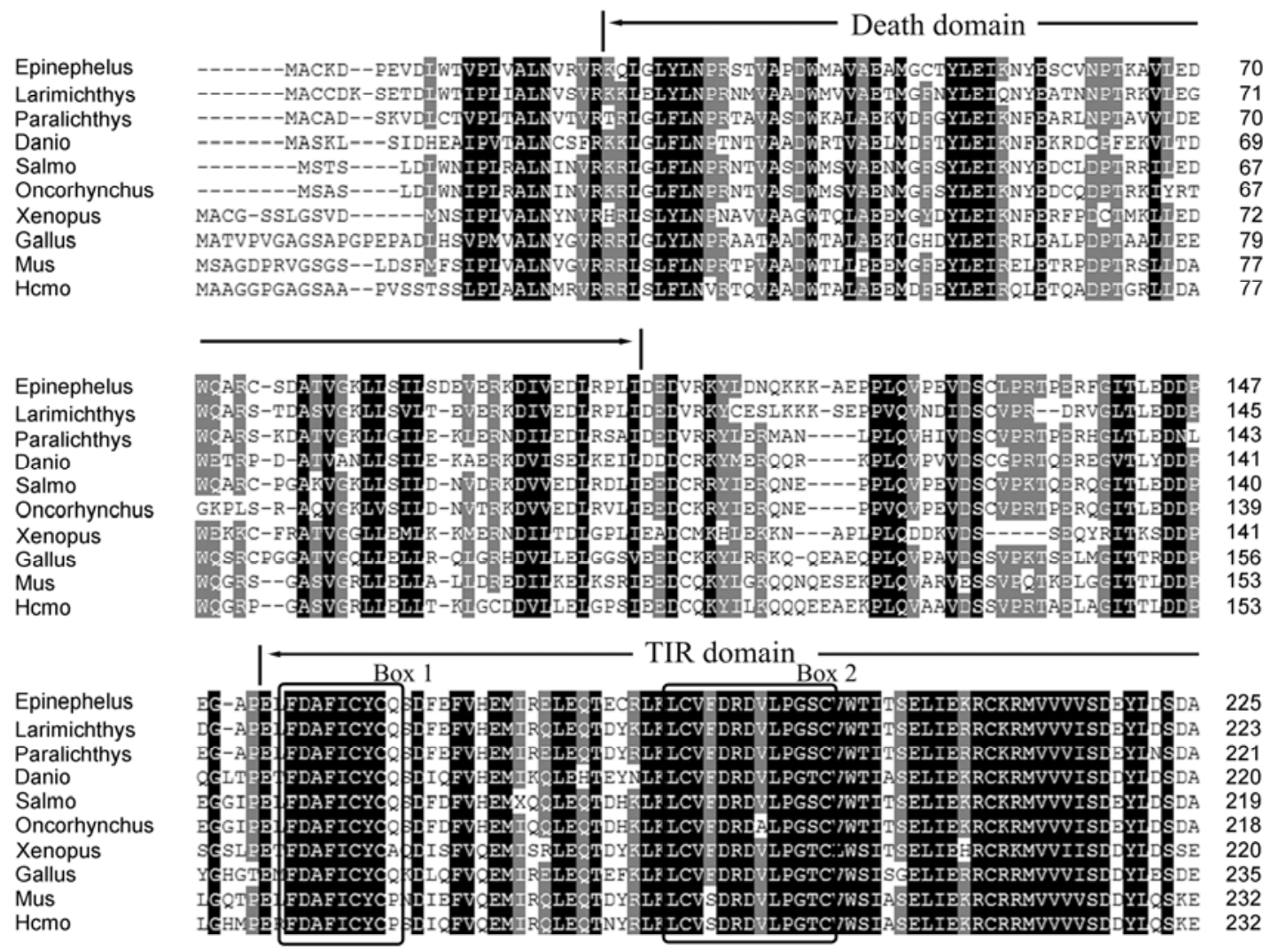

TIR domain

Epinephelus

Larimichthys

Paralichthys

Danio

Salmo

Oncorhynchus

Xenopus

Gallus

Mus

$\mathrm{Hcmo}$
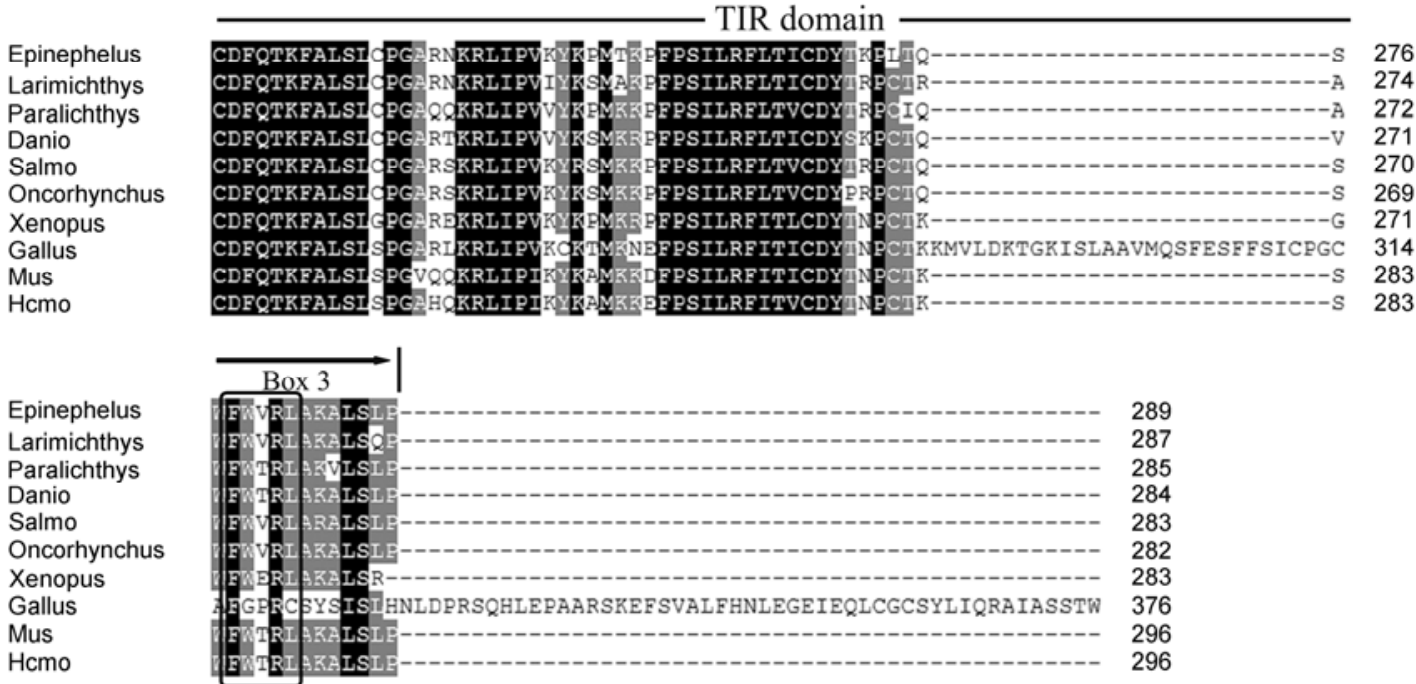

Figure 2 Multiple-sequence alignment of the deduced amino acid sequence of Og-MyD88 with other reported MyD88 variants. Completely conserved residues across all species are shaded in black. The N-terminal death domain and C-terminal TIR domain are marked with arrows. The three highly conserved motifs within the TIR domain are boxed. The GenBank accession numbers of the aligned MyD88 sequences are listed in Table 2. 


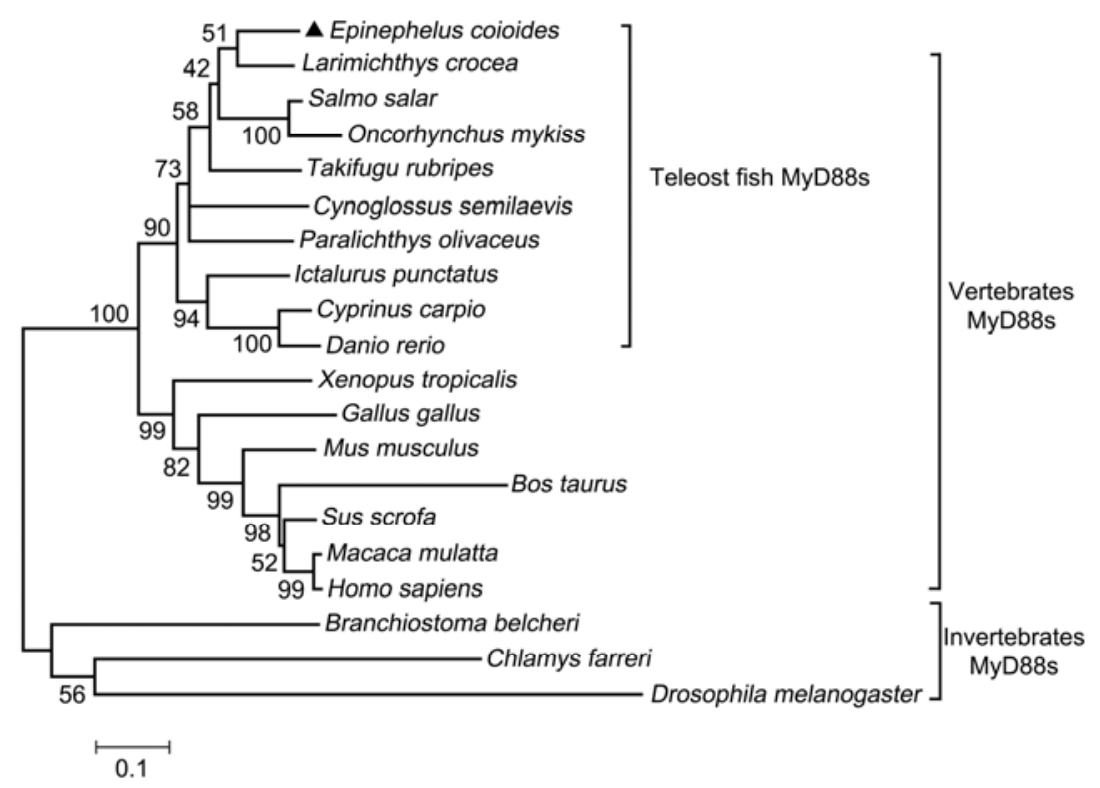

Figure 3 Phylogenetic analysis of Og-MyD88 with other reported MyD88 variants in vertebrates and invertebrates. The phylogenetic tree of the aligned amino acid sequences was constructed by the neighbor-joining method within MEGA 3.1. Numbers at branch nodes represent the bootstrap majority consensus values of 1000 replicates. The GenBank accession numbers of the analyzed MyD88 sequences are listed in Table 2.

Table 2 GenBank accession numbers of reported MyD88 proteins

\begin{tabular}{ll}
\hline \multicolumn{1}{c}{ MyD88 protein } & GenBank accession number \\
\hline Epinephelus coioides & ADK89123 \\
Larimichthys crocea & ACL14361 \\
Paralichthys olivaceus & BAE94195 \\
Salmo salar & ABV59003 \\
Oncorhynchus mykiss & NP_001117893 \\
Cynoglossus semilaevis & ACU31062 \\
Takifugu rubripes & BAF91189 \\
Danio rerio & AAI64642 \\
Cyprinus carpio & ADC45019 \\
Ictalurus punctatus & ACD81929 \\
Xenopus tropicalis & NP_001016837 \\
Chlamys farreri & ABB76627 \\
Branchiostoma belcheri & ABQ32299 \\
Drosophila melanogaster & NP_610479 \\
Gallus gallus & NP_001026133 \\
Mus musculus & AAC53013 \\
Bos taurus & AAY22119 \\
Sus scrofa & NP_001093393 \\
Macaca mulatta & NP_001124153 \\
Homo sapiens & AAB49967 \\
\hline
\end{tabular}

\subsection{Expression profiles of Og-MyD88}

In healthy fish, a constitutive but variable mRNA expression of Og-MyD88 was observed in all tissues examined, including liver, spleen, head kidney, kidney, skin, brain, intestine, heart, skin, muscle and stomach (Figure 4(a)). Og-MyD88 was expressed strongly in spleen, head kidney, kidney, liver, skin and intestine, all of which are immune-related tissues. Lower expression levels were observed in heart, stomach and brain, with the lowest level found in muscle.

To determine whether Og-MyD88 was involved in the grouper immune responses to viral challenges, the temporal
mRNA expression of Og-MyD88 in the spleen was analyzed after challenging with SGIV. The SGIV-injected fish showed greater severity in disease symptoms (including lower feed intake and hemorrhagic intestine or spleen) after 24 hpi compared with the PBS injected fish. The RT-qPCR results revealed a 2.6-6.1-fold increase in expression of Og-MyD88 in SGIV-stimulated groupers (Figure 4(b)). In detail, the level of Og-MyD88 transcripts in grouper spleens decreased at 4 hpi. However, levels sharply increased from 8 hpi (2.6-fold induction) and gradually reached a peak (6.1-fold induction) at $48 \mathrm{hpi}$, then transcript levels began to drop but were retained at a level 3.5-fold higher than that in the PBS-injected control fish.

\subsection{Og-MyD88 activates NF- $\mathrm{B}$ in HEK-293 cells}

Transfection and the luciferase reporter assay were used to investigate whether Og-MyD88 had the ability to induce $\mathrm{NF}-\kappa \mathrm{B}$ activity as reported for mammalian MyD88 genes. HEK-293 cells were transiently transfected with the NF- $\kappa$ B reporter plasmid, together with the indicated Og-MyD88 expression vector. In addition, $\mathrm{pRL}$-TK vector was included to normalize the Firefly luciferase activity. As shown in Figure 5(a), full length Og-MyD88 activated NF- $\kappa B$ in a dose-dependent manner in HEK-293 cells. Furthermore, compared with luciferase activity observed in the control cells, overexpressed Og-MyD88 gave a 6.5-fold greater induction, as well as nearly 5-fold greater luciferase activity induced by the sole death domain of Og-MyD88. In TIR domain expressed cells, there were no significant changes in Firefly luciferase activity compared with those of the control cells (Figure 5(b)). These data suggest that Og-MyD88, 

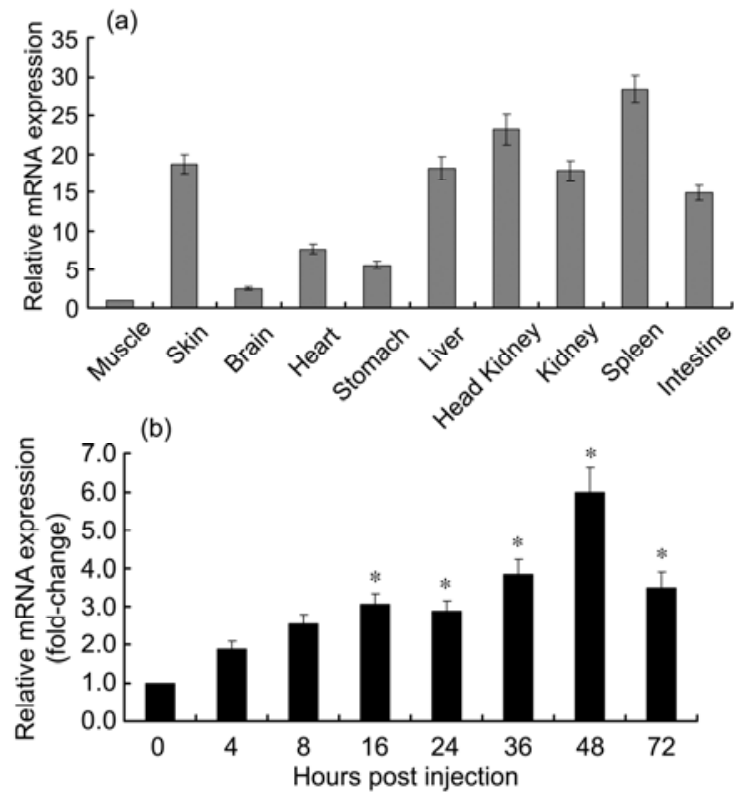

Figure 4 RT-qPCR analysis of the expression profiles of Og-MyD88. (a) The relative mRNA level of Og-MyD88 in different tissues. Data are expressed as a ratio to Og-MyD88 transcripts in muscle. (b) Temporal expression analysis of Og-MyD88 mRNA in grouper spleen at 4, 8, 16, 24, 36,48 and $72 \mathrm{~h}$ after challenge with SGIV. Og-MyD88 mRNA expression was normalized to that in PBS-injected control fish. Vertical bars represented the mean $\pm \mathrm{SD}(n=5)$ and significant differences of Og-MyD88expression between the challenged and control samples are indicated with an asterisk $(*)$ at $P<0.05$.
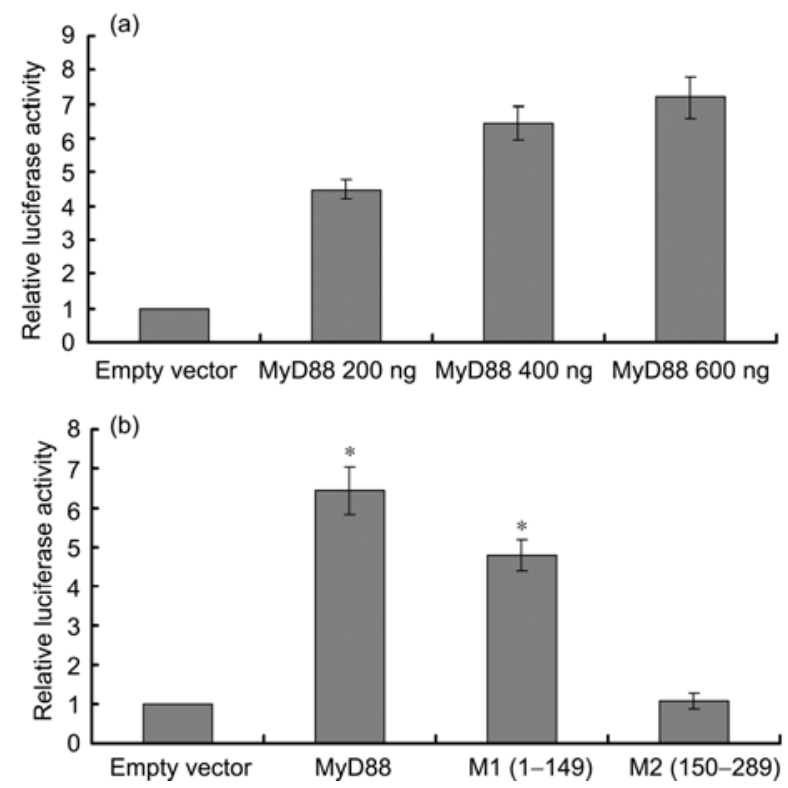

Figure 5 Og-MyD88 overexpression induced NF- $\mathrm{kB}$ activity in HEK-293 cells. Cells were co-transfected with pcDNA3.1 or indicated Og-MyD88 expression vector, together with pNF-kB-Luc and pRL-TK vector. (a) Dose-response of pcDNA-MyD88 vector on induction of NF- $\mathrm{KB}$ activity. (b) NF- $\kappa B$ activation analysis of full-length MyD88, N-terminal death domain region (M1: 1-149) and C-terminal TIR region (M2: 150-289). Firefly and Renilla luciferase activity in cell lysates were measured 24 hpi and the data are expressed as the fold stimulation compared with pcDNA3.1 transfected cells. All data are expressed as mean relative stimulation \pm SD from three separate experiments with each performed in triplicate. together with MyD88 in other reported fish, share similar characteristics to MyD88 in mammalian species in activating the $\mathrm{NF}-\kappa \mathrm{B}$ signaling cascade.

\subsection{Over-expressed Og-MyD88 inhibits SGIV infection in GS cells}

To assess the impact of Og-MyD88 overexpression on the replication of SGIV, the stably transfected GS/pcDNAMyD88 and GS/pcDNA cells were infected with SGIV and the SGIV replication kinetics were compared over the course of infection. The Og-MyD88 expression level in GS/pcDNA-MyD88 cells was much higher than that in GS/pcDNA cells (Figure 6(a)). Figure 6(b) shows the replication kinetics of SGIV in these two stably transfected GS cell lines. In detail, the SGIV titers in both stably transfected GS cells began to increase from $12 \mathrm{hpi}$ and gradually reached maximum titer at 72 hpi. However, the virus replicated more slowly in Og-MyD88-expressing GS cells (GS/pcDNA-MyD88) in which the viral titers yielded were about 3-6 times lower than those in empty vector transfected cells, 18 to $72 \mathrm{hpi}$, indicating over-expression of Og-MyD88 has an inhibitory impact on the replication kinetics of SGIV. Meanwhile, the CPE caused by SGIV appeared earlier and more prominently in the empty vector stably transfected cells, compared with that in the GS/pcDNA-MyD88 cells (data not shown).

\section{Discussion}

Toll like receptors are considered key pattern recognition receptors (PRRs) of invading microbes by detecting distinct PAMPs and triggering the host's innate immunity and adaptive immune responses [37,38]. Subsequent to recognition of PAMPs by TLRs, a set of adaptor proteins are recruited selectively, including MyD88, TIRAP, TRIF and TRAM [10]. Notably, upon activation by PAMPs, almost all TLRs directly or indirectly recruit MyD88 as the adaptor protein to propagate the downstream signaling, except TLR3 which uses TRIM as its adaptor protein [16]. MyD88 binds directly to the TIR domain of TLR5/7-9 and TLR11 [39,40], while TLR1/2/4/6 requires TIRAP as a "bridge" to interact with MyD88 [41,42]. This adaptor protein interacts with certain protein kinases and triggers the downstream signaling cascades leading to activation of transcription factor $\mathrm{NF}-\kappa \mathrm{B}$, proinflammatory cytokines and type I IFN induction, which play essential roles in host immune responses to eliminate invading microorganisms [9].

In the present study, a novel TLR/IL-1R adaptor protein, MyD88, was identified and characterized from spleen cDNA of orange-spotted grouper, E. coioides. The full length cDNA of Og-MyD88 is $1682 \mathrm{bp}$, including an ORF of 870 bp encoding a polypeptide of 289 amino acids. Similar to other reported fish $M y D 88$ genes, the $3^{\prime}$-UTR of 

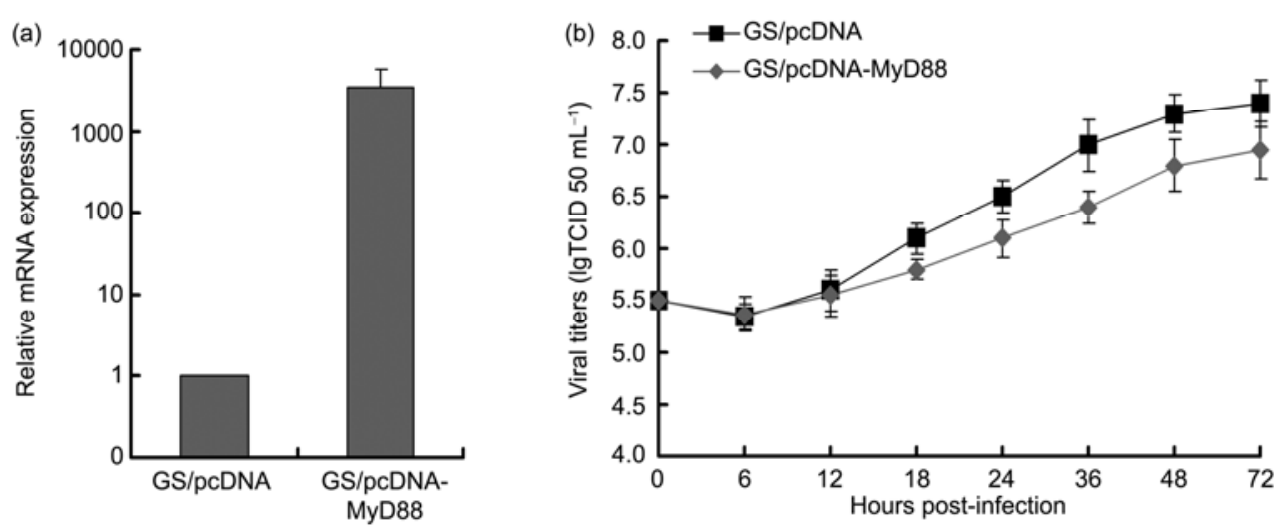

Figure 6 Effect of Og-MyD88 overexpression on SGIV replication in GS cells. (a) Overexpression of Og-MyD88 in GS/pcDNA-MyD88 cells was confirmed by RT-qPCR. (b) Cell-free viruses were collected from the lysates of two stably transfected GS cell lines infected by SGIV at different time points (0, $6,12,18,24,36,48$ and $72 \mathrm{hpi}$ ) and the viral titer was measured using the $\mathrm{TCID}_{50}$ method.

Og-MyD88 contains two ATTTA instability motifs, the presence of which is a characteristic of some fish inflammatory mediator-coding genes and is believed to be responsible for destabilizing mRNA by regulating degradation or suppressing translation [43]. A comparison of the amino acid sequence of Og-MyD88 with other MyD88 variants from a variety of species, including $L$. arimichthys crocea, $P$. olivaceus, D. rerio, S. salar, O. mykiss, X. tropicalis, $G$. gallus, Mus musculus and Homo sapiens, revealed that Og-MyD88 possesses two typical conserved domains found in all MyD88 variants: a death domain in the N-terminus and a TIR domain in the C-terminus. Besides the typical conserved domains, three highly conserved motifs (Box 1, Box 2 and Box 3), proposed as essential for the interaction of MyD88 with TLRs and IL-1R, were found in the TIR region of Og-MyD88 [44]. All sequence characteristics of the Og-MyD88 gene suggest that MyD88 in grouper fish, together with MyD88 in other fish species, may share similar functions to those observed in mammals.

The expression of MyD88 has been studied in many species. MyD88 in mammalian and other vertebrates are mainly expressed in immune tissues. In this study, ubiquitous expression of Og-MyD88 was observed in all tested grouper tissues, which is in agreement with observations reported in other fish species [35,38,39,42]. Og-MyD88 showed higher expression levels in immune response-related tissues, including spleen, head kidney, kidney, skin and intestine. The tissue distribution pattern of Og-MyD88 is similar to MyD88 in other species, including mammalian [18], avian [20], amphibian [21] and other fish [28,30,31].

The SGIV, a double-stranded DNA virus belonging to the genus Ranavirus, family Iridoviridae, has been regarded as a cause of serious systemic diseases among feral, cultured and ornamental groupers in recent years [33]. However, functional gene studies of this virus and the host immunity information against SGIV infection are still limited. In the present study, MyD88 transcripts in the grouper spleen were markedly up-regulated after SGIV stimulation, indi- cating that MyD88 is potentially involved in grouper response to SGIV infection. Up-regulation of Og-MyD88 may be due to proliferation or recruitment of MyD88-expressing immune cells in the grouper spleen, which is reported to be the most susceptible target organ for SGIV infection $[45,46]$. Our results are in agreement with those observed in the Japanese flounder and rock bream [28,31].

Mammalian MyD88 variants have been shown to activate the NF- $\kappa \mathrm{B}$ signaling cascade. In human Huh7 hepatoma cells, expression of the full-length human MyD88 resulted in activation of NF- $\kappa \mathrm{B}$ activity and its N-terminal region polypeptide (amino acids 1-151) was still capable of inducing NF- $\mathrm{KB}$ activity. Conversely, the dominant negative mutant of MyD88 (amino acids 152-296) did not induce NF- $\kappa \mathrm{B}$ activity [47]. Recently, several reports have highlighted the potency of piscine MyD88 variants in inducing $\mathrm{NF}-\kappa \mathrm{B}$ activity in different cell lines, confirming the functional conservation of MyD88 during the evolution of vertebrate innate immunity from fish to mammals $[29,48]$. In this study, we examined the impact of full-length and different functional domains of grouper MyD88 on NF- $\mathrm{BB}$ activation in HEK-293 cells. Overexpressed Og-MyD88 and its $\mathrm{N}$-terminal death domain, showed the ability to elicit high NF- $\kappa \mathrm{B}$ luciferase activity. While the sole TIR domain of Og-MyD88, which is considered to be essential for binding to TLRs or other adaptors, did not activate NF- $\kappa B$ at all. These data are consistent with previous studies of MyD88 from different species and indicate MyD88 in grouper fish may play similar roles in triggering the host NF- $\kappa \mathrm{B}$ signaling cascade resulting in proinflammatory cytokine induction and elimination of invading microorganisms.

Previous studies have shown that mammalian MyD88 is involved in host immune responses against a variety of viral infections [47,49,50]. The ability of MyD88 to recruit IRAKs for activation of NF- $\mathrm{B}$ and induction of proinflammatory cytokines, especially the involvement of TLR7/8/9-MyD88 in triggering IFN signaling during viral infection, highlights the importance of MyD88 in control- 
ling viral infection and virus replication [51]. Notably, recent studies on MyD88 in Atlantic salmon, showed the ability of fish MyD88 to interact with IRFs (IRF3 and IRF7A/B) and modulate the IRF-induced type I IFN response [52]. Although our previous studies showed grouper IRF7 was probably involved in host anti-SGIV immune responses [53], endogenous expression of IRF7 in GS cells was retained at an undetectable level, even after SGIV infection (data not shown). This finding excludes the possibility that grouper MyD88 exerts anti-SGIV functions in an MyD88/IRF7-dependent IFN signaling manner in GS cells. However, based on findings from the in vivo pathogenesis experiment and luciferase reporter assay, we sought to determine whether grouper MyD88 was involved in responding to SGIV infection in GS cells. After obtaining GS cells stably expressing Og-MyD88, the antiviral activity of Og-MyD88 was evaluated. In conjunction with the upregulated Og-MyD88 transcript levels observed in SGIV-stimulated grouper fish, as well as the ability of Og-MyD88 to activate the NF- $\mathrm{kB}$ signaling cascade, overexpressed $\mathrm{Og}-\mathrm{MyD} 88$ was able to inhibit the replication kinetics of SGIV in GS cells compared with infected control cells. These data raise the possibility that $\mathrm{Og}-\mathrm{MyD} 88 \mathrm{might}$ be involved in the host antiviral immune response and may inhibit virus replication by activating NF-kB-dependent induction of proinflammatory cytokines.

In conclusion, a novel MyD88 gene (Og-MyD88) was successfully cloned from grouper, E. coioides, based on 454-pyrosequencing and RACE approaches. Og-MyD88 shared a conserved death domain and TIR domain with MyD88 in other fish, mammal, chicken, frog and scallop. Og-MyD88 was highly expressed in grouper immune-related tissues and was up-regulated in response to viral pathogen in vivo. Furthermore, full-length Og-MyD88 and its $\mathrm{N}$-terminal death domain, were able to activate NF- $\mathrm{KB}$ and showed an ability to inhibit replication of SGIV in GS cells. These data indicate that Og-MyD88 is implicated in the innate defense response of $E$. coioides and is a likely important, effective component for response to invading viral pathogens. Further studies on identifying SGIV specific PAMPs and the exact signaling cascades that Og-MyD88 is implicated in, will be helpful for progression of antiviral therapeutic and vaccine development.

This work was supported by the National Basic Research Program of China (2012CB114402), the Knowledge Innovation Program of the Chinese Academy of Sciences (KZCX2-YW-BR-08 and KZCX2-EW-Q213) and the National Natural Science Foundation of China (30725027 and 30930070).

1 Ellis A E. Innate host defense mechanisms of fish against viruses and bacteria. Dev Comp Immunol, 2001, 25: 827-839

2 Magnadóttir B. Innate immunity of fish (overview). Fish Shellfish Immunol, 2006, 20: 137-151

3 Larsen R, Rokenes T P, Robertsen B. Inhibition of infectious pancreatic necrosis virus replication by Atlantic salmon Mx1 protein. J Virol, 2004, 78: 7938-7944
4 Robertsen B. The interferon system of teleost fish. Fish Shellfish Immunol, 2006, 20: 172-191

5 Akira S, Uematsu S, Takeuchi O. Pathogen recognition and innate immunity. Cell, 2006, 124: 783-801

6 Honda K, Taniguchi T. IRFs: Master regulators of signaling by Toll-like receptors and cytosolic pattern-recognition receptors. Nat Rev Immunol, 2006, 6: 644-658

7 Honda K, Takaoka A, Taniguchi T. Type I interferon gene induction by the interferon regulator factor family of transcription factors. Immunity, 2006, 25: 349-360

8 Janeway C A Jr, Medzhitov R. Innate immune recognition. Annu Rev Immunol, 2002, 20: 197-216

9 Krishnan J, Selvarajoo K, Tsuchiya M, et al. Toll-like receptor signal transduction. Exp Mol Med, 2007, 39: 421-438

10 Kawai T, Akira S. Signaling to NF-kappaB by Toll-like receptors. Trends Mol Med, 2007, 13: 460-469

11 Horng T, Barton G M, Medzhitov R. TIRAP: An adapter molecule in the Toll signaling pathway. Nat Immunol, 2001, 2: 835-841

12 Yamamoto M, Sato S, Mori K, et al. Cutting edge: A novel Toll/IL-1 receptor domain-containing adapter that preferentially activates the IFN-beta promoter in the Toll-like receptor signaling. J Immunol, 2002, 169: 6668-6672

13 Oshiumi H, Matsumoto M, Funami K, et al. TICAM-1, an adaptor molecule that participates in Toll-like receptor 3-mediated interferon- $\beta$ induction. Nat Immunol, 2003, 4: 161-167

14 Yamamoto M, Sato S, Hemmi H, et al. TRAM is specifically involved in the Toll-like receptor 4-mediated MyD88-independent signaling pathway. Nat Immunol, 2003, 4: 1144-1150

15 Belinda L W, Wei W X, Hanh B T, et al. SARM: A novel Toll-like receptor adaptor, is functionally conserved from arthropod to human. Mol Immunol, 2008, 45: 1732-1742

16 Yamamoto M, Sato S, Hemmi H, et al. Role of adaptor TRIF in the MyD88-independent toll-like receptor signaling pathway. Science, 2003, 301: 640-643

17 Lord K A, Hoffman-Liebermann B, Liebermann D A. Nucleotide sequence and expression of a cDNA encoding MyD88, a novel myeloid differentiation primary response gene induced by IL6. Oncogene, 1990, 5: 1095-1097

18 Bonnert T P, Garka K E, Parnet P, et al. The cloning and characterization of human MyD88: A member of an IL-1 receptor related family. FEBS Lett, 1997, 402: 81-84

19 Strausberg R L, Feingold E A, Grouse L H, et al. Generation and initial analysis of more than 15,000 full-length human and mouse cDNA sequences. Proc Natl Acad Sci USA, 2002, 99: 16899-16903

20 Wheaton S, Lambourne M D, Sarson A J, et al. Molecular cloning and expression analysis of chicken MyD88 and TRIF genes. DNA Seq, 2007, 18: 480-486

21 Prothmann C, Armstrong N J, Rupp R A. The Toll/IL-1 receptor binding protein MyD88 is required for Xenopus axis formation. Mech Dev, 2000, 97: 85-92

22 Qiu L, Song L, Yu Y, et al. Identification and characterization of a myeloid differentiation factor 88 (MyD88) cDNA from Zhikong scallop Chlamys farreri. Fish Shellfish Immunol, 2007, 23: 614-623

23 Tauszig-Delamasure S, Bilak H, Capovilla M, et al. Drosophila MyD88 is required for the response to fungal and Gram-positive bacterial infection. Nat Immunol, 2001, 3: 91-97

24 Meylan E, Tschopp J. Toll-like receptors and RNA helicases: Two parallel ways to trigger antiviral responses. Mol Cell, 2006, 22: 561-569

25 Wesche H, Henzel W J, Shillinglaw W, et al. MyD88: An adaptor that recruits IRAK to the IL-1 receptor complex. Immunity, 1997, 7: 837-847

26 Meijer A H, Gabby Krens S F, Medina Rodriguez I A, et al. Expression analysis of the Toll-like receptor and TIR domain adaptor families of zebrafish. Mol Immunol, 2004, 40: 773-783

27 Rebl A, Goldammer T, Fischer U, et al. Characterization of two key molecules of teleost innate immunity from rainbow trout (Oncorhynchus mykiss): MyD88 and SAA. Vet Immunol Immunopathol, 2009, 131: $122-126$ 
28 Takano T, Kondo H, Hirono I, et al. Identification and characterization of a myeloid differentiation factor 88 (MyD88) cDNA and gene in Japanese flounder, Paralichthys olivaceus. Dev Comp Immunol, 2006, 30: 807-816

29 Skjæveland I, Iliev D B, Strandskog G, et al. Identification and characterization of TLR8 and MyD88 homologs in Atlantic salmon (Salmo salar). Dev Comp Immunol, 2009, 33: 1011-1017

30 Yao C L, Kong P, Wang Z Y, et al. Molecular cloning and expression of MyD88 in large croaker Pseudosciaena crocea. Fish Shellfish Immunol, 2009, 26: 249-255

31 Whang I, Lee Y, Kim H, et al. Characterization and expression analysis of the myeloid differentiation factor 88 (MyD88) in rock bream Oplegnathus fasciatus. Mol Biol Rep, 2011, 38: 3911-3920

32 Qin Q W, Lam T J, Sin Y M, et al. Electron microscopic observations of a marine fish iridovirus isolated from brown-spotted grouper, Epinephelus tauvina. J Virol Methods, 2001, 98: 17-24

33 Qin Q W, Chang S F, Ngoh-Lim G H, et al. Characterization of a novel ranavirus isolated from grouper Epinephelus tauvina. Dis Aquat Org, 2003, 53: 1-9

34 Qin Q W, Wu T H, Jia T L, et al. Development and characterization of a new tropical marine fish cell line from grouper, Epinephelus coioides susceptible to iridovirus and nodavirus. J Virol Methods, 2006, 131: $58-64$

35 Droege M, Hill B. The genome sequencer FLX ${ }^{\mathrm{TM}}$ system-longer reads, more applications, straight forward bioinformatics and more complete data sets. J Biotechnol, 2008, 136: 3-10

36 Reed L J, Muench H. A simple method of estimating fifty percent endpoints. Am J Epidemiol, 1938, 27: 493-497

37 Akira S, Takeda K. Toll-like receptor signaling. Nat Rev Immunol, 2004, 4: 499-511

38 Pasare C, Medzhitov R. Toll-like receptors: Linking innate and adaptive immunity. Adv Exp Med Biol, 2005, 560: 11-18

39 Hemmi H, Kaisho T, Takeuchi O, et al. Small anti-viral compounds activate immune cells via the TLR7 MyD88-dependent signaling pathway. Nat Immunol, 2002, 3: 196-200

40 Hoshino K, Kaisho T, Iwabe T, et al. Differential involvement of IFN-beta in Toll-like receptor-stimulated dendritic cell activation. Int Immunol, 2002, 14: 1225-1231

41 Yamamoto M, Sato S, Hemmi H, et al. Essential role for TIRAP in activation of the signaling cascade shared by TLR2 and TLR4.
Nature, 2002, 420: 324-329

42 Horng T, Barton G M, Flavell R A, et al. The adaptor molecule TIRAP provides signaling specificity for Toll-like receptors. Nature, 2002, 420: 329-333

43 Sachs A B. Messenger RNA degradation in eukaryotes. Cell, 1993, 74: 413-421

$44 \mathrm{Xu} \mathrm{Y,} \mathrm{Tao} \mathrm{X,} \mathrm{Shen} \mathrm{B,} \mathrm{et} \mathrm{al.} \mathrm{Structural} \mathrm{basis} \mathrm{for} \mathrm{signal} \mathrm{transduction}$ by the Toll/interleukin-1 receptor domains. Nature, 2000, 408: 111-115

45 Huang C H, Zhang X B, Gin K Y H, et al. In situ hybridization of a marine fish virus, Singapore grouper iridovirus with a nucleic acid probe of major capsid protein. J Virol Meth, 2004, 117: 123-128

46 Teng Y, Hou Z, Gong J, et al. Whole-genome transcriptional profiles of a novel marine fish iridovirus, Singapore grouper iridovirus (SGIV) in virus-infected grouper spleen cell cultures and in orange-spotted grouper, Epinephulus coioides. Virology, 2008, 377: 39-48

47 Lin S, Wu M, Xu Y, et al. Inhibition of hepatitis B virus replication by MyD88 is mediated by nuclear factor-kappaB activation. Biochim Biophys Acta, 2007, 1772: 1150-1157

48 Rebl A, Rebl H, Liu S, et al. Salmonid Tollip and MyD88 factors can functionally replace their mammalian orthologues in TLR-mediated trout SAA promoter activation. Dev Comp Immunol, 2010, 35: 81-87

49 Szretter K J, Daffis S, Patel J, et al. The innate immune adaptor molecule MyD88 restricts West Nile virus replication and spread in neurons of the central nervous system. J Virol, 2010, 84: 12125-12138

50 Seo S U, Kwon H J, Song J H, et al. MyD88 signaling is indispensable for primary influenza A virus infection but dispensable for secondary infection. J Virol, 2010, 84: 12713-12722

51 Pichlmair A, Reis e Sousa C. Innate recognition of viruses. Immunity, 2007, 27: 370-383

52 Iliev D B, Sobhkhez M, Fremmerlid K, et al. MyD88 interacts with interferon regulatory factor (IRF) 3 and IRF7 in Atlantic salmon (Salmo salar): Transgenic SsMyD88 modulates the IRF-induced type I interferon response and accumulates in aggresomes. J Biol Chem, 2011, 286: 42715-42724

53 Cui H, Yan Y, Wei J, et al. Identification and functional characterization of an interferon regulatory factor 7-like (IRF7-like) gene from orange-spotted grouper, Epinephelus coioides. Dev Comp Immunol, 2011, 35: 672-684

Open Access This article is distributed under the terms of the Creative Commons Attribution License which permits any use, distribution, and reproduction in any medium, provided the original author(s) and source are credited. 